\title{
O julgamento da ADPF no 186: uma reflexão à luz do debate Honneth-Fraser
}

\author{
The Trial of the Allegation of Unconstitutionality \\ number 186: an insight based on Honneth-Fraser
}

\author{
Maria Eugenia Bunchaft ${ }^{\star}$
}

\section{Resumo}

O tema das desigualdades raciais revelou-se como um dos mais controversos da sociedade brasileira. Como se sabe, a escravidão deixou marcas profundas, inspirando relações humanas assimétricas fundadas atualmente em um racismo cordial. No Brasil, assumiu especial relevância na discussão sobre a legitimidade da adoção de cotas raciais no ensino superior o julgamento da ADPF no 186, interposta pelo Partido Democratas, em face do CESPE/UNB, questionando atos administrativos nos quais utilizaram-se critérios raciais para admissão de alunos, sob argumento de violação aos artigos $1^{\circ}, 2^{\circ}, 3^{\circ}, 5^{\circ}$, 37, 207 e 208 da Constituição Federal (BRASIL, 1988). No presente estudo, focaremos dois aspectos da discussão sobre as políticas de ação afirmativa para afrodescendentes: a questão da legitimidade constitucional e dos fundamentos filosóficos que elucidam a temática. Nesse particular, o debate HonnethFraser é fundamental para a compreensão da temática das cotas raciais para afrodescendentes. À luz desse embate teórico, pretendemos demonstrar, com base no teor do voto do Ministro Celso de Mello, que o debate sobre o quem da temática das cotas raciais transcende a moldura keynesiana-westfaliana dos públicos nacionais, tal como descrita por Fraser. Outrossim, pretendemos demonstrar que a concretização objetiva do princípio da igualdade material, fundamento utilizado pelo STF no referido julgamento, representa, à luz da teoria de Honneth, a efetivação de promessas historicamente estabelecidas pelas instituições sociais.

Palavras-chave: Minorias. Cotas raciais. Reconhecimento. Direitos fundamentais.

Professora do Programa de Pós-Graduação em Direito da UNISINOS. Pós-doutora em Filosofia pela UFSC. Doutora e mestre em Teoria do Estado e Direito Constitucional pela PUC-Rio. Graduada em Direito pela PUC-Rio. Professora de Direito Constitucional da Graduação em Direito na UNISINOS. Email: mbunchaft@ig.com.br 


\section{Abstract}

The issue of racial inequality has been revealed as one of the most controversial of Brazilian society. As it is known, slavery left deep marks in Brazilian society, raising asymmetric human relations currently based in a whitewashed racism. In Brazil, particular importance was given in the discussion about the legitimacy of the adopting racial quotas in higher education trial ADPF $n$. 186. In this sense, the Allegation of Unconstitutionality number 186 was filed by the Democratic Party in the face of CESPE / UNB, challenging administrative acts in which it was used racial criteria for admission of students, in case of violation of articles 1, 2, 3, 5, 37, 207 and 208 of the Brazilian Constitution. In this study, we will focus on two aspects of the discussion about affirmative action for Afro-descendants: the question of constitutional legitimacy and philosophical underpinnings that depict the topic. In this respect, the Fraser - Honneth debate is fundamental to understand the issue of racial quotas for Afro-descendants. In light of this theoretical clash, we intend to demonstrate based on the content of the opinion of Justice Mello, the debate on whom the subject of racial quotas transcends the Keynesian - Westphalian frame of the national government, as described by Fraser. Furthermore, we intend to demonstrate that the objective embodiment of the principle of substantive equality, the foundation used by the Supreme Court in this judgment, is in the light of the theory of Honneth, the realization of promises historically established social institutions.

Keywords: Minorities. Racial quotas. Recognition. Fundamental rights.

\section{Introdução}

O tema das desigualdades raciais revelou-se como um dos mais controversos da sociedade brasileira. Nesse sentido, a realidade educacional tornou-se elemento de discussão entre ativistas políticos ligados ao movimento negro, pesquisadores, professores e antropólogos. Como se sabe, a escravidão deixou marcas profundas, inspirando relações humanas assimétricas fundadas atualmente em um racismo cordial.

Nesse quadro teórico, a Constituição de 1988 inaugurou um novo cenário jurídico, pois a Assembleia Constituinte contou com ampla 
participação popular, na qual as reivindicações do movimento negro encontraram terreno fértil. No presente estudo, focaremos dois aspectos da discussão sobre adoção de cotas raciais no ensino superior: o da legitimidade constitucional e o dos fundamentos filosóficos que elucidam a temática.

Como se sabe, existem argumentos contrários à implementação de políticas de ação afirmativa no ensino superior, sob a alegação, por exemplo, de que a raça não pode ser considerada uma categoria capaz de justificar políticas de ação afirmativa no ensino superior para afrodescendentes. Alega-se também que o resultado da adoção de cotas raciais seria um racismo institucionalizado, inspirando um processo de divisão da sociedade. Pretendemos analisar cada um desses argumentos à luz de fundamentos constitucionais.

É de se mencionar que três decretos contemplam as discussões tematizadas em conferências nacionais para direitos de afrodescendentes: o Decreto $n^{\circ} 4.886$, de 20 de novembro de 2003 (BRASIL, 2003), que estabelece a Política Nacional de Promoção à Igualdade Racial; o Decreto n 6.872, de 2009 (BRASIL, 2009), que aprovou o Plano Nacional de Promoção à Igualdade Racial; e, por fim, a presidenta Dilma Rousseff assinou, na III Conferência Nacional de Promoção da Igualdade Racial, o Decreto n 8.136, de 2013 (BRASIL, 2013), que aprova o regulamento do Sistema Nacional de Promoção da Igualdade Racial, instituído pela Lei no 12.288, de 2010 (BRASIL, 2010). Em 2012, a presidenta já havia sancionado a Lei $n^{\circ} 12.711 / 2012$ (BRASIL, 2012)1.

Recentemente, foi sancionada a Lei $n^{\circ}$ 12.990/2014 (BRASIL, 2014), que determina cotas em concursos federais, estabelecendo que

\footnotetext{
Quanto à produção legislativa, o Estatuto da Igualdade Racial não era exatamente aquele que pretendia a UNEGRO. O Senador Demóstenes Torres, relator à época, havia encaminhado emendas modificativas e supressivas que descaracterizavam aspectos relevantes do Estatuto, como a supressão de parte dos artigos atinentes à saúde da população negra e das cotas na universidade. Em 8 de junho de 2010, a UNEGRO posicionou-se contrariamente à incorporação das emendas de Demóstenes. Prevaleceu o posicionamento da SEPPIR e do Senador Paulo Paim, tendo em vista que o projeto tramitava há mais de dez anos no Congresso.
} 
$20 \%$ das vagas sejam reservadas para candidatos que se declararem negros ou pardos. A lei prevê que, caso verificado que a declaração de negro ou pardo seja falsa, haverá a eliminação do candidato. Se este já tiver sido nomeado, poderá ter sua admissão anulada, além da possibilidade de sofrer processo administrativo.

Nessa evolução jurídica, assumiu especial relevância na discussão sobre a legitimidade da adoção de cotas raciais no ensino superior o julgamento daADPF n 186 pelo STF, interposta pelo Partido Democratas, em face do CESPE/UNB, questionando atos administrativos nos quais utilizaram-se critérios raciais para admissão de alunos, sob argumento de violação aos artigos $1^{\circ}, 2^{\circ}, 3^{\circ}, 5^{\circ}, 37,207$ e 208 da Constituição Federal (BRASIL, 1988).

No entanto, os afrodescendentes compõem $50,6 \%$ da população brasileira, estando em extrema desvantagem em todos os indicadores sociais, como renda, acesso ao saneamento básico, saúde e índice de mortalidade infantil. O racismo cordial permeia as relações humanas no Brasil, tendo como reflexo as conhecidas discriminações vinculadas e incorporadas à vida cotidiana - por exemplo, o elevador de serviço e o quarto de empregada.

Indubitavelmente, a discussão sobre as ações afirmativas para afrodescendentes também possui um significado filosófico, que será explorado no presente trabalho. Nesse particular, o debate HonnethFraser é fundamental para a compreensão da discussão sobre cotas raciais para afrodescendentes. Honneth (2003a) delineou uma filosofia política que associa uma teoria do desenvolvimento psíquico à evolução moral da sociedade.

Nesse particular, o filósofo estabeleceu um diálogo com Fraser (2003), teórica feminista e professora da Nova Escola para Pesquisa Social de Nova York. Indubitavelmente, o debate entre Honneth e Fraser, que resultou no livro Redistribution or Recognition, é fundamental para elucidar a análise do julgamento da ADPF $n^{\circ} 186$. No entanto, é necessário atualizar tal debate à luz de novos ensaios teóricos de ambos os autores. 
Honneth (2011) sublinha que uma sociedade justa é aquela na qual as diferentes esferas sociais (esfera íntima, mercado e Estado Democrático) concretizam a liberdade individual. Como salienta Sobottka (2013, p. 166):

[...] enquanto em Luta por Reconhecimento, as relações intersubjetivas são descritas como um processo em que simultaneamente se socializam e individualizam os participantes, em O Direito da Liberdade, a própria liberdade é descrita como constituída através de relações intersubjetivas.

Diante dessa estrutura conceitual, podemos indagar: quais os fundamentos filosóficos que legitimam a adoção de políticas de ações afirmativas no ensino superior? Por um lado, pretendemos investigar se a raça pode ser utilizada como categoria analítica capaz de atribuir direitos e benefícios sociais a determinados grupos, e se os argumentos de justiça distributiva e pluralismo legitimam a adoção de políticas de cotas raciais em universidades.

Por outro lado, propugnamos analisar, à luz do debate HonnethFraser, em que medida tais instrumentais teóricos revelam-se coerentes com os desafios propostos pela adoção de políticas de cotas raciais nas universidades, tendo em vista a necessidade de uma ênfase teórica na dimensão institucional do reconhecimento. A visão de justiça defendida por Fraser (2003a) era bidimensional. A partir do momento em que a questão da moldura de justiça torna-se suscetível à contestação, termina por permitir a visibilidade de uma terceira dimensão da justiça, não abordada anteriormente e descrita por Fraser (2010): a da representação.

Assim, para Fraser (2010), se as regras de decisão política que estruturam os processos públicos de contestação impedem que determinados indivíduos tenham a oportunidade de participar plenamente como pares, surge a falsa representação da política comum. Em que medida a adoção de cotas raciais serve para desconstruir mecanismos institucionais na esfera do reconhecimento, da distribuição 
e da representação que impedem a paridade de participação de afrodescendentes? E em que medida relaciona-se à ideia de liberdade social, tal como descrita por Honneth?

Por meio de um método hermenêutico e monográfico (estudo de caso), e tendo como técnica de pesquisa a análise do julgamento da ADPF no 186 pelo STF, propugnamos sustentar, com base no teor do voto do Ministro Celso de Mello, que o debate sobre o quem da temática das cotas raciais transcende a moldura keynesiana-westfaliana dos públicos nacionais descrita por Fraser.

Por um lado, assumimos o objetivo de defender que Honneth, ao propugnar sanar o déficit sociológico da Teoria Crítica, termina por suscitar o que Werle e Melo (2013) denominam de "déficit político da Teoria Crítica", no sentido de inexistir em sua teoria qualquer preocupação em explicitar um princípio de justificação recíproca e universal em que os próprios cidadãos pudessem decidir quais formas de reconhecimento e princípios de justiça são legítimos ou ilegítimos.

Por outro lado, pretendemos demonstrar que a concretização objetiva do princípio da igualdade material, fundamento utilizado pelo STF no referido julgamento, representa, à luz da teoria de Honneth, a efetivação de promessas historicamente estabelecidas pelas instituições sociais. Feitas essas considerações, passamos à análise do debate Honneth-Fraser.

\section{0 debate Honneth-Fraser}

De início, é premente lecionar que a filosofia de Honneth (2003a) pressupõe a construção da identidade como expressão de lutas intersubjetivas por reconhecimento mútuo. A identidade humana, portanto, surge a partir da intersubjetividade. Por meio de relações intersubjetivas, os indivíduos estabelecem três formas de interação social. A primeira delas é a autoconfiança, que se expressa nas relações de amor e amizade, através das quais a unidade originalmente simbiótica entre mãe e filho irá romper-se, originando instâncias de autonomia apoiadas pela dedicação materna. 
A segunda forma de reconhecimento ocorre por meio da atribuição de direitos universais que permitem aos indivíduos alcançarem um sentido de autorrespeito. É por meio de relações juridicamente institucionalizadas que os cidadãos estabelecem sua autoimagem. Por fim, a terceira forma de reconhecimento constitui a dimensão da autoestima, através da qual os indivíduos são socialmente estimados por seus atributos singulares na esfera da divisão do trabalho de uma comunidade (BUNCHAFT, 2009).

Sob esse aspecto, Honneth (2003a) apresenta um conceito de luta por reconhecimento a partir da dimensão "ética da injustiça", fornecendo novas bases filosóficas para sua proposta de renovar a Teoria Crítica, compreendendo os padrões concretos de desrespeito como a base motivacional capaz de inspirar a gramática dos conflitos sociais. Honneth (apud SOBBOTKA; SAAVEDRA, 2012) modifica sua estrutura conceitual, pois, em vez de três esferas do reconhecimento, elas passam a ser formas de expressão da liberdade, sendo esta hierarquicamente superior.

Nessa perspectiva, para Honneth (2003a), somente quando os indivíduos se propõem a rearticular as relações de interação social é possível superar a tensão afetiva inerente ao potencial emancipatório das experiências de sofrimento. É oportuno resgatar uma passagem que elucida o pensamento do autor:

Para chegar a uma autorrelação bem-sucedida, ele depende do reconhecimento intersubjetivo de suas capacidades e de suas realizações; se uma tal forma de assentimento social não ocorre em alguma etapa de seu desenvolvimento, abre-se na personalidade como que uma lacuna psíquica, na qual entram as reações emocionais negativas como a vergonha ou a ira. Daí a experiência do desrespeito estar sempre acompanhada de sentimentos afetivos que, em princípio, podem revelar ao indivíduo que determinadas formas de reconhecimento lhe são socialmente denegadas. (HONNETH, 2003a, p. 220) 
Nessa concepção filosófica, o autor propugna investigar os pressupostos necessários que ensejam situações de vulnerabilidade moral, porquanto as experiências de desrespeito e humilhação impedem as condições necessárias para uma autorrealização plena. Honneth (2003a) apropria-se do pensamento de Dewey, segundo o qual os sentimentos são compreendidos como a repercussão afetiva do sucesso ou insucesso de nossas intenções práticas.

Em suma, o filósofo alemão analisa que, em situações de vulnerabilidade moral, os sujeitos ofendidos, quando seus parceiros de interação não correspondem às suas expectativas normativas, terminam por expressar sentimentos de vexação, que "consistem num rebaixamento do sentimento de valor próprio" (HONNETH, 2003a, p. $222)^{2}$.

Nessa trajetória teórica, Honneth (2003b) estabeleceu um debate com Fraser (2003a) sobre os fundamentos filosóficos das teorias do reconhecimento, diálogo expresso no livro Redistribution or Recognition. A divergência entre os autores surge porque Fraser propõe articular distribuição material de recursos e reconhecimento cultural por meio de uma política econômica socialista, capaz de combater as diferenças sociais, e uma perspectiva desconstrutivista, que implicaria não em políticas estreitas de autenticidade de grupo, mas em um processo de desconstrução identitária.

Sob esse prisma, Fraser procura romper com uma abordagem psicológica do reconhecimento, contrapondo-se à desvinculação entre as dimensões econômica e cultural e rompendo com uma perspectiva

Não obstante, o autor apresenta uma concepção teórica fundamental para atender aos desafios inerentes a situações de opressão na sociedade: o conceito de invisibilidade social. Nas palavras de Honneth (2001, p. 2), "sujeitos humanos são visíveis a outro sujeito, na medida em que este pode identificá-los de acordo com as características do relacionamento, como pessoas claramente definidas por propriedades", ou seja, quando nossos parceiros de interação social reconhecem nossas singularidades e atributos. Em síntese, de acordo com Honneth (2001, p. 1), "a história cultural oferece inúmeros exemplos nos quais o dominador expressa sua superioridade social ao não perceber aqueles que dominam." Um sujeito pode confirmar a própria visibilidade somente forçando seu parceiro de interação social a reconhecer suas singularidades e propriedades que formam uma identidade. 
dicotômica que privilegia as questões distributivas ou se restringe às injustiças culturais. Adivisão social entre homossexuais e heterossexuais, por exemplo, não se baseia apenas em critérios econômicos, pois os homossexuais ocupam diferentes posições sociais na divisão do trabalho e não constituem uma classe explorada. Nas palavras da autora:

[...] a divisão é enraizada, diferentemente, na ordem de status da sociedade como padrões institucionalizados de valores culturais que constroem a heterossexualidade como natural e normativa e a homossexualidade como perversa e desprezada. (FRASER, 2003a, p. 18)

Trata-se de padrões normativos institucionalizados nas diversas áreas do Direito, relativas à família, intimidade e igualdade.

Sob essa ótica, gays e lésbicas sofrem uma série de injustiças econômicas como consequência da subordinação na ordem de status, tendo em vista a institucionalização de normas heterossexistas que negam, por exemplo, uma ampla gama de benefícios sociais e familiares concedidos às relações heterossexuais. Indubitavelmente, para a autora, "superar a homofobia e o heterossexismo exige a mudança da ordem sexual de status, desinstitucionalizando padrões valorativos heteronormativos e substituindo-os por padrões que expressem igual respeito por gays e lésbicas" (FRASER, 2003a, p. 19).

Quanto às classes sociais nas quais os indivíduos são tradicionalmente explorados, são necessários remédios redistributivos, que visam superar injustiças econômicas. No caso dos negros, a discriminação combina características de exploração econômica com elementos de discriminação sexual e de ausência de representação, de forma que a injustiça é tridimensional. Trata-se de formas de injustiça primárias e cooriginárias. A discriminação racial é uma categoria híbrida decorrente da injustiça econômica e da ordem de status na sociedade, porque a raça estrutura a divisão fundamental entre trabalho produtivo remunerado ocupado por homens brancos e trabalho mal remunerado não remunerado atribuído aos negros. 
Nesse cenário, seria necessário combater a injusta divisão de trabalho que discrimina economicamente os afrodescendentes, assim como os padrões eurocêntricos institucionalizados, os quais "são relativamente independentes da economia política e não são meramente superestruturais. Eles, portanto, não podem ser superados apenas por redistribuição, mas exigem medidas adicionais independentes de reconhecimento." (FRASER, 2003a).

Com efeito, Fraser (2001) estabelece uma distinção entre remédios afirmativos e transformativos. A ação afirmativa seria uma forma de redistribuição afirmativa voltada para superar a injustiça racial na economia, permitindo que pessoas negras tenham participação justa nos empregos existentes e acesso à educação, mantendo intactos a natureza e o número desses empregos e vagas. O reconhecimento afirmativo, voltado para reparar a injustiça racial na cultura, contempla o nacionalismo cultural e a valorização da cultura negra, enquanto deixa intacto o código binário branco/negro que atribui sentido à relação. $A$ autora destaca que tais estratégias seriam problemáticas.

Segundo Fraser (2001), como no caso do gênero, a redistribuição afirmativa não afeta o nível profundo no qual a economia política é influenciada pela raça; não ataca a divisão por raça dos explorados e do trabalho em excesso nem a divisão por raça de ocupações humildes e valorizadas no trabalho assalariado. Ao deixar intactas as estruturas profundas que geram a desvantagem racial, deve fazer realocações contínuas. O resultado não é apenas sublinhar a diferenciação de raça, mas também marcar as pessoas de cor como deficientes e insaciáveis. Portanto, elas podem ser vistas como beneficiárias privilegiadas de tratamento especial.

Desse modo, de acordo com a autora, o reconhecimento afirmativo, embora possa inspirar progressos no que se refere à descentralização de normas eurocêntricas, pode terminar por suscitar refluxo e reações hostis das pessoas brancas. A teórica defende uma redistribuição transformativa voltada para reparar a injustiça racial na esfera econômica, que consiste em uma forma de antirracismo socialista democrático ou de antirracismo social democrático (FRASER, 2001). 
Diferentemente, o reconhecimento transformativo consiste na desestruturação do eurocentrismo por meio da desestabilização de dicotomias raciais. O objetivo do desconstrutivismo antirracista é uma "cultura na qual são substituídas dicotomias hierárquicas raciais por redes de diferenças cruzadas múltiplas que são fluidas e não massificadas" (FRASER, 2001, p. 278).

Nesse contexto, discordamos parcialmente de Fraser (2001), pois, se por um lado entendemos que a injustiça racial situa-se nas esferas do reconhecimento e da redistribuição, e que, efetivamente, as cotas raciais não atacam a estrutura econômica profunda; por outro, sustentamos que o papel das medidas de ação afirmativa é permitir que parcela da população sem voz na sociedade tenha a oportunidade de alcançar uma paridade de participação, para, em um segundo momento, protagonizar mudanças reais efetivas na estrutura econômica subjacente.

Nessalinha de raciocínio, incorporamos parcialmente o instrumental teórico de Fraser (2001) para legitimar a adoção de políticas de cotas raciais nas universidades. À medida que se ampliam as possibilidades de acesso dos afrodescendentes no mercado de trabalho e no ensino superior, desinstitucionalizam-se os mecanismos institucionais estabelecidos na esfera do reconhecimento e da redistribuição, os quais impedem a paridade de participação de uma parcela excluída da população, viabilizando que, em um momento posterior, esta se torne protagonista de transformações econômicas estruturais expressas por meio de uma redistribuição transformativa.

Indubitavelmente, o modelo de status de Fraser (2003a) pretende contrapor-se ao modelo teórico delineado por Honneth (2003b; 2003c), porquanto as políticas identitárias - ao focalizarem a perspectiva da autorrealização - negligenciam os padrões institucionalizados de desvalorização cultural que impedem os indivíduos de se tornarem parceiros plenos na esfera da paridade de participação.

Fraser (2003a) focaliza não as concepções de vida boa, mas a desinstitucionalização dos padrões de valores culturais que impedem a paridade de participação do indivíduo enquanto parceiro pleno da vida 
social. Para Honneth (2003b), a privação de direitos a minorias sexuais se expressa através de uma experiência de desrespeito, que conduz à perda do autorrespeito e da capacidade de referir-se a si mesmo como um igual dentro da interação social. Fraser (2003a), por sua vez, sublinha que a questão fundamental não é focalizar as experiências de sofrimento decorrentes de contextos de vulnerabilidade moral, como pretende Honneth, mas as efetivas implicações do não reconhecimento na esfera da participação paritária.

Nesse quadro teórico, "o modelo de status é deontológico e não sectário", pois "não apela para uma concepção de autorrealização ou bem. Diferentemente, apela para uma concepção de justiça que pode e deve - ser aceita por aqueles com concepções divergentes de bem." (FRASER, 2003a, p. 31). A ideia é desvincular-se de demandas de reconhecimento identitárias atinentes a concepções de autorrealização, que inspirariam uma postura sectária.

Nesse particular, para Honneth (2003b; 2003c), a possibilidade do surgimento de indivíduos autônomos, que desenvolvem livremente sua identidade, depende do desenvolvimento intacto de relações de reconhecimento. Para Fraser (2003a), a questão é: o que fazer com nossa identidade autônoma? Criar uma sociedade justa, na qual todos tenham a possibilidade de participar.

Em face dessa leitura, tanto Honneth (2003b; 2003c) como Fraser (2003a) desenvolvem uma visão instrumental do reconhecimento. Este seria um meio para alcançar determinados fins: a identidade pessoal intacta ou a participação paritária plena. Trata-se de algo do qual cada um poderia dispor por meio de um ato de declaração ou vontade individual. A crítica de Kompridis (2008) a Fraser (2003a) direcionase à compreensão da autora do reconhecimento construído como um remédio para a injustiça.

Assim, Fraser (2003a) pressupõe uma estrutura deontológica baseada no ideal da paridade de participação. Em vez de tratar o reconhecimento como instrumental para a autorrealização individual, ela o trata como instrumental para adquirir status como parceiro pleno 
na interação social. Já para Honneth (2003b; 2003c), o reconhecimento seria uma constante antropológica que funciona como uma condição necessária para a formação de uma identidade pessoal intacta.

Diante dessa estrutura conceitual, Kompridis (2008) analisa dois problemas na concepção instrumental de Fraser (2003a). Na sua interpretação, a perspectiva de Fraser (2003a) medicaliza a questão do reconhecimento, da identidade e da justiça como se estivéssemos lidando com uma doença no corpo político para a qual o remédio apropriado deve ser prescrito.

Ademais, para Kompridis (2008), Fraser (2003a) instrumentalizaria algo que não seria instrumentalizável. Kompridis (2008) leciona que o reconhecimento não seria algo do qual pudéssemos dispor ou medir em porções apropriadas para pessoas apropriadas em um tempo apropriado. Podemos distribuir recursos econômicos por meio da maquina estatal, mas reconhecimento não é algo que pode ser redistribuído. Por outro lado, segundo Kompridis (2008), tão importante quanto os mecanismos legais são as mudanças nas práticas de reconhecimento.

Sob esse aspecto, segundo o autor, Fraser (2003a) insiste que o erro do não reconhecimento não depende da presença de efeitos psicológicos. Mas, questiona Kompridis (2008), isso significaria que os efeitos do não reconhecimento são moralmente irrelevantes? Kompridis (2008) indaga sobre o que teria levado Fraser (2003a) a considerar os efeitos psicológicos do não reconhecimento como irrelevantes para julgar a injustiça. Por uma questão de objetividade, para Fraser (2003a), em sua crítica a Honneth (2003b; 2003c), seria relevante o que realmente conta a título de injustiça em contraposição ao que é meramente vivenciado como injustiça.

Em suma, Fraser (2003a) assevera que devemos apelar não para uma esfera de experiências subjetivas que não podem ser publicamente verificáveis, mas para impedimentos externamente manifestados e publicamente verificáveis que impedem algumas pessoas de serem membros plenos da sociedade. Na perspectiva de Kompridis (2008), uma estratégia seria recorrer a discursos despersonalizados de justiça. Tais discursos descentrados oferecem "um ponto de referência empírico 
mais plausível e objetivo para avaliar as pretensões de reconhecimento que o sofrimento inarticulado" (KOMPRIDIS, 2008, p. 299).

Diferentemente do segundo, o primeiro não é protegido da contestação pública, mas tem a vantagem de ser sujeito ao escrutínio do debate público. De acordo com Kompridis (2008), a distinção entre o que conta a título de injustiça e o que é vivenciado como injustiça é muito problemática. Se, por um lado, a experiência subjetiva é notoriamente incerta como fonte de justificação, ela também é insubstituível e fonte de inteligibilidade absolutamente necessária. Segundo Kompridis (2008), a identificação do não reconhecimento deve passar tanto pela experiência subjetiva como pelos discursos descentrados.

Em síntese, os discursos despersonalizados podem atuar como corretivos das experiências subjetivas e estas, como corretivas dos primeiros. O autor defende um elo recíproco entre as experiências subjetivas e os discursos descentrados. Elas devem permear os discursos para assegurar que o conteúdo deles não seja vazio e que eles não sejam fonte de alienação. O não reconhecimento deve ter a capacidade de atribuir sentido ao seu sofrimento mediante discursos descentrados ${ }^{3}$.

Sob essa ótica, a crítica de Kompridis (2008) a Fraser (2003a) é no sentido de que seria altamente improvável que os vocabulários disponíveis fossem plenamente adequados àquilo que necessita ser reconhecido. A questão é: como o sofrimento inarticulado irá tornar-se articulado? Nesse ponto, a articulação deve preceder a reivindicação,

\footnotetext{
Sob esse prisma, Fraser (2003a) privilegia os últimos em detrimento dos primeiros, concebendo o não reconhecimento como desprovido da noção de sofrimento. Honneth (2003c), por sua vez, atribui ênfase às experiências subjetivas. Mas, se o que necessita ser alegado não pode ser externamente manifestado e publicamente verificável em discursos em vocabulários atuais disponíveis, e se os discursos e vocabulários exigidos não podem simplesmente ser criados da noite para o dia, para Kompridis (2008, p. 300), a questão é: como podemos confiar nos "padrões de verificação pública que pressupõem a adequação dos discursos atuais disponíveis e os vocabulários de avaliação e justificação?". De fato, de acordo com o autor, é precisamente porque "não podemos presumir a adequação justificatória dos discursos atuais, que a experiência subjetiva deve sempre ser um ponto de referência normativo indispensável de resistência, contestação e transformação" (KOMPRIDIS, 2008, p. 300).
} 
pois, muitas vezes, há uma experiência de ausência de voz, de inexpressividade ou de capacidade para articular experiências de sofrimento.

Kompridis (2008) alega que Fraser (2003a) minimiza a importância da inovação linguística para dar expressão às injustiças não articuladas e inominadas. Fraser (2008) contra-argumenta que não haveria nada em sua abordagem afirmando que vocabulários existentes de justificação sejam adequados para revelar danos que ainda não foram publicamente articulados.

Nesse cenário, a autora (2008) refere-se a uma categoria que desenvolveu por mais de vinte anos sobre os "meios de comunicação e interpretação". Estes são mais bem situados para expressar as perspectivas dos seus estratos mais favorecidos do que dos grupos subordinados. Impedindo a participação paritária, essa tendência estabelecida pelos meios de interpretação e comunicação cria laços assimétricos e uma injustiça institucionalizada.

Com efeito, para Fraser (2008, p. 335), “cada luta histórica contra injustiça tem envolvido a criação de novos vocabulários para articulação de injustiças que previamente são inominadas". A segunda onda do feminismo inventou expressões como "estupro", "assédio sexual", entre outras inovações linguísticas. A ausência de voz a que se refere Kompridis (2008), para Fraser (2008), está vinculada à necessidade de criação de novos contrapúblicos subalternos que ampliam novas interpretações de necessidades que não são ouvidas na esfera pública oficial.

Nesse contexto, é por meio desses contrapúblicos de resistência que os movimentos sociais ampliam a gama de conhecimento de injustiças publicamente articuladas, expandindo o universo da razão pública ${ }^{4}$. Na perspectiva de Kompridis (2008), o reconhecimento

4 Para Fraser (1992 p. 123), estes constituem "arenas discursivas paralelas nas quais os membros dos grupos socialmente subordinados inventam e circulam contradiscursos para formular interpretações opostas de suas identidades, interesses e necessidades". 
implica tanto o paradigma da justiça (defendido por Fraser) como o da autorrealização (defendido por Honneth), insinuando a necessidade de integrar ambos.

No entanto, alega que o reconhecimento seria melhor compreendido como uma questão de liberdade no sentido foulcaultiano: uma preocupação sobre como nós nos autogovernamos. Qualquer tentativa de reduzir o reconhecimento a uma interpretação monista seria uma leitura errônea. Kompridis (2008) critica a perspectiva delineada por Fraser (2003a) de direcionar a crítica para a justiça institucionalizada.

Outrossim, em relação à alegação de Kompridis (2008), segundo a qual a Teoria Crítica deve se preocupar tanto com justiça como com a autorrealização, Fraser (2008) alega que a Teoria Crítica deve "priorizar a crítica da injustiça institucionalizada de forma a abrir espaço para formas legítimas de autorrealização". Tratando-se a justiça como a primeira virtude, ela deve "equalizar as condições sobre as quais as várias interpretações de florescimento humano são formuladas, debatidas e perseguidas" (FRASER, 2008, p. 334).

Mas, em Scales of Justices (2010), a estrutura conceitual da justiça, anteriormente focada na perspectiva bidimensional (redistribuição e reconhecimento), incorpora uma terceira perspectiva: a da representação. Esta irá complementar o instrumental de Fraser, sendo capaz de contemplar a dimensão estruturante do enquadramento da justiça em sociedades globais. Portanto, a terceira dimensão da justiça é o político, que "diz respeito à natureza da jurisdição do Estado e das regras de decisão pelas quais ele estrutura as disputas sociais" (FRASER, 2009, p. 19).

Não é mais suficiente elucidar sobre o que é e quem são os destinatários da justiça. Nas palavras de Fraser (2009, p. 19), “ao estabelecer regras de decisão, a dimensão política também estipula os procedimentos de apresentação e resolução das disputas tanto na dimensão econômica e cultural", e conclui: "ela revela não apenas quem pode fazer reivindicações por redistribuição e reconhecimento, mas também como tais reivindicações devem ser introduzidas no debate e 
julgadas". Dessa maneira, raça é uma categoria tridimensional situada na estrutura econômica, na ordem de status e na esfera da representação ${ }^{5}$.

Recentemente, Honneth (2011), por sua vez, publicou um novo livro, Das Recht der Freiheit. Este decorreu de uma estratégia teórica mais ampla, capaz de abranger uma teoria da justiça que se expresse na forma de uma análise da sociedade. Nas palavras de Honneth (2011, p. 9):

isso somente seria possível se as esferas constitutivas da nossa sociedade fossem compreendidas como a corporificação institucional de determinados valores, cuja pretensão imanente de realização possa servir como indicador dos princípios de justiça especificados em cada esfera.

Em suma, a descrição dos princípios normativos que legitimam e estruturam as instituições sociais conecta-se a uma reconstrução normativa que pressupõe uma análise crítica dos potenciais emancipatórios intrínsecos às instituições sociais, garantindo a relevância social da sua teoria da justiça. A liberdade passa a expressar-se em três dimensões diferentes. A liberdade negativa pressupõe a inexistência de impedimentos externos à concretização da vontade individual e à possibilidade de atuar sem necessidade de justificar-se a terceiros.

\footnotetext{
Assim, os afrodescendentes, no Brasil, estariam submetidos tanto à injustiça na esfera da distribuição, no âmbito do reconhecimento, como na dimensão da representação - ambas as dimensões se reforçam mutuamente. Sob esse aspecto, o político é uma dimensão conceitualmente distinta da justiça que não se reduz à perspectiva econômica ou cultural, apesar de estarem entrelaçadas. O como da justiça assume um papel constitutivo nos procedimentos democraticamente estruturados dos processos políticos decisórios e será a categoria necessária para configurar uma teoria crítica que identifica contextos de exclusão que integram os três níveis. Nessa perspectiva, a autora defende uma esfera pública transnacional, na qual há uma rearticulação dos processos decisórios, superando as fronteiras dos estados nacionais territorialmente situados. A categoria "esfera pública", situada territorialmente, sofre uma revisão crítica à luz de uma abordagem transnacional. Fraser (2010) alega que a teoria da justiça para tempos anormais deve rejeitar pressuposições cientificas. Fatos incontroversos quanto a quem é afetado, decorrentes de interpretações dos historiadores, teorias sociais e pressuposições normativas também são objeto de discussão. As questões do quem são submetidas a um processo dialógico que irá delimitar as reivindicações dos desfavorecidos.
} 
A segunda dimensão pressupõe a liberdade expressa em uma forma reflexiva. Esta pressupõe a possibilidade de realizar julgamentos morais de normas que irão pautar a conduta individual, problematizando as exigências impostas pela sociedade e pelas instituições quando não atendam a argumentos universalizáveis. Trata-se da racionalidade kantiana na qual o indivíduo distancia-se de suas paixões e, como sujeito moral, passa a orientar-se por uma moralidade que trata cada ser humano como um fim em si mesmo.

Sob esse prisma, as instituições sociais somente podem ser consideradas justas quando satisfazem as expectativas legítimas dos cidadãos de efetivar essas formas de liberdade. Por fim, há uma terceira dimensão da liberdade, denominada social, articulando-se ao papel da intersubjetividade no reconhecimento. Nas palavras de Honneth (2011, p. 86): "O sujeito, em última análise, somente é livre, quando encontra outro com o qual estabelece uma relação de reconhecimento recíproco, porque divisa nos objetivos dele uma condição para a realização dos seus próprios objetivos."

A formação da identidade do sujeito autônomo depende de relações intersubjetivas de reconhecimento, estando ligada à execução de papéis sociais estabelecidos pelas instituições ${ }^{6}$. A liberdade social somente é possível nas instituições sociais, sendo um elemento constitutivo de liberdade dos indivíduos. Honneth (2011) considera a concepção hegeliana de reconhecimento essencial para as instituições da liberdade em sociedades modernas, sendo efetivada pelo Estado, mercado e sociedade civil.

Nesse ponto, o autor concebe "a instituição da esfera pública democrática como um espaço social intermediário no qual cidadãs e cidadãos devem formar aquelas convicções passíveis de um consenso

Analisando o tema, leciona Okochi (2012, p. 14): "por meio da incorporação da autorrealização nas relações sociais que o reconhecimento recíproco desempenha um papel fundamental". Para Okochi (2012, p. 14), "a liberdade é possível à medida que os sujeitos encontram outros com quem podem ter relações de reconhecimento recíproco, dentro de suas práticas institucionais, e podem encontrar condições para sua própria autorrealização". 
geral que deveriam ser respeitadas pelo processo legislativo por meio de procedimentos próprios do Estado de Direito" (HONNETH, 2011, p. 471). Honneth (2011) sublinha como um dos fatores centrais para a construção de uma esfera pública democrática a cristalização do ideal do patriotismo constitucional que permita fluxos de comunicação entre governo e população.

Por fim, Honneth (2011) enumera cinco pressupostos que irão viabilizar um maior nível de concretização da liberdade social: garantias jurídicas de participação política dos indivíduos, espaço comunicativo comum, um sistema diferenciado de mídia, motivação para engajamento participativo dos cidadãos em discussões públicas, e cristalização de um sentimento de solidariedade cívica. Este último pressuposto está intimamente vinculado à capacidade de as políticas de ação afirmativa inspirarem um contato paritário entre as etnias, favorecendo o pluralismo nas universidades.

\section{0 debate constitucional sobre políticas de ação afirmativa}

É mister frisar que a Constituição de 1988 resguarda a dignidade humana e o respeito aos direitos fundamentais, assumindo também especial relevância a proteção ao princípio da igualdade. E, sem dúvida, a isonomia assume uma dimensão não apenas formal, mas material, condicionando a atuação positiva do Estado de reduzir as desigualdades sociais. A partir da interpretação sistemática do texto constitucional, podemos constatar que a Constituição pretende tutelar a isonomia material.

Nesse cenário, o art. $3^{\circ}$ estabelece: "construir uma sociedade livre, justa e solidária" (inciso I), "erradicar a pobreza e marginalização e reduzir as desigualdades sociais e regionais" (inciso III) e "promover o bem de todos, sem preconceitos de origem, raça, sexo, cor, idade e quaisquer outras formas de discriminação" (inciso IV) (BRASIL, 1988). Assim, são necessárias atuações positivas do Estado voltadas para a redução das desigualdades raciais e sociais. A desigualdade, 
entretanto, não tem um aspecto puramente social, mas também envolve uma dimensão étnico-racial.

Com efeito, a discussão sobre se a raça pode ser uma categoria analítica a ser utilizada para legitimar políticas de ação afirmativa remonta ao mito da democracia racial, usado como mecanismo ideológico de construção da nação. Freire (1973) defende que a miscigenação foi um fator positivo para a cultura brasileira. Esse discurso foi objeto de apropriação pelas elites brasileiras na ditadura militar, com o intuito de negar que as relações raciais no Brasil não seriam tensas e, portanto, não tínhamos problemas com a inclusão do negro? .

Nesse contexto, alguns autores alegam que, se o Estado atribui direitos com base na raça, o resultado é a divisão das sociedades, pois estimula-se que a identidade seja reivindicada com base na raça. Benjamim (2007, p. 30) destaca que o conceito de raças humanas "foi remetido ao museu onde estão expostas à galhofa as afirmações de que a Terra é plana, de que habitamos o centro do universo, de que os corpos graves tendem ao repouso e outras idéias que desorganizaram o pensamento da humanidade ao longo da História".

A generalidade dos argumentos dos artigos que compõem o referido livro é no sentido de que seria ilegítima uma medida supostamente antirracista que toma por base características raciais para oferecer vantagens, deixando dúvidas quanto à sua eficiência igualitária, acirrando as disparidades e polarizando o ódio racial entre brancos e negros.

Vale citar, ainda, que, de acordo com a "Carta de Cento e Treze Cidadãos Antirracistas Contra as Leis Raciais", entregue ao Ministro do

Desse modo, o mito da democracia racial apoia-se em três pressupostos. Em primeiro lugar, a ideia de que, no Brasil, as relações raciais não são tensas nem explosivas, mas baseadas na cordialidade. Ademais, esse mito contribuiu para divulgar a ideia de que a raça não poderia ser utilizada como categoria analítica na atribuição de direitos e oportunidades aos indivíduos. Esse pensamento decorre da concepção segundo a qual é a classe social que explica e define a atribuição de direitos e oportunidades aos cidadãos. A categoria raça é desconsiderada para explicar as dificuldades de mobilidade social dos indivíduos. 
STF, Gilmar Mendes, quando o legislador fala em "tratar desigualmente os desiguais”, está, em princípio, falando em desigualdades superáveis, como aquelas que dividem pobres e ricos. É oportuno transcrever tal assertiva:

[...] deve-se tratar desigualmente os que têm menos, ou seja, os pobres, para que deixem de ser pobres. Mas, ao contrário da pobreza, a diferença racial não é algo que se possa descartar depois de um processo de privilégio imposto pelo Estado. Pobres deixarão de ser pobres com o acesso às Universidades, e esse é o objetivo do tratamento diferencial. Mas quem deixará de ser negro depois de ser obrigado a se definir como tal para ser merecedor de um direito? [...] (CARTA... 2012).

Nesse particular, a principal questão é: combater o racismo com base na raça seria uma contradição? A ideia de classificação dos agrupamentos humanos com base na raça, desde a Segunda Guerra Mundial, foi desmistificada pelos biólogos, sendo considerada uma tentativa de ideologias racistas de justificar a divisão injusta dos benefícios sociais. Tal diferenciação não mais subsiste, o que encontrou embasamento nas descobertas desenvolvidas pelo Projeto Genoma Humano.

Não obstante, não compartilhamos de tal entendimento, pois o fato de não existir raça sob o ponto de vista biológico não impede que benefícios sociais e direitos sejam atribuídos com base em construções sociais da categoria raça. Se a raça não existe do ponto de vista biológico, não significa que ela não exista sociologicamente. É uma categoria social que explica as relações intersubjetivas assimétricas e práticas discriminatórias de uns indivíduos perante outros.

Em face dessa leitura, nas palavras de Guimarães (1999, p. 9), "raça é um conceito que não corresponde a nenhuma realidade natural. Trata-se, ao contrário, de um conceito que denota tão-somente uma forma de classificação social baseada numa atitude negativa frente a certos grupos sociais". Raça é uma construção social presente nas relações sociais que distribui desigualmente direitos e vantagens a 
certos indivíduos com base em uma classificação racial presente na sociedade.

Assim, outro ponto é a questão do difícil acesso do negro ao ensino superior. Muitos alegam que o verdadeiro fator que impossibilita esse acesso não é a cor, mas a defasagem do sistema educacional no qual está inserida a maioria dos negros, ou seja, as escolas públicas. Adotar cotas raciais nada mais seria do que afastar o dever do Estado em promover educação de forma universal e de qualidade, tratando o problema de acesso às universidades públicas de forma coletiva.

Para muitos, a despeito da diferença racial nas universidades públicas, as desigualdades econômicas são as que determinam o acesso universitário, e não a desigualdade racial. Por essa razão, a política de cotas, em essência, afastaria o dever de promoção da educação pelo Estado. Essas desigualdades, no âmbito educacional, provêm da situação precária do próprio sistema educacional público do país.

Diante dessa estrutura conceitual, a generalidade dos argumentos sustenta que, por meio de cotas raciais, conserva-se intacta uma estrutura de ensino público. Dessa forma, elas aniquilariam o valor do mérito acadêmico em favor de um privilégio de cor e sustentariam que seus beneficiários fossem percebidos como incapazes de ascender à posição superior por méritos próprios. Desse modo, argumentam, reforça-se a associação de inferioridade, agravando a estigmatização da população negra.

Outrossim, é necessário corrigir a inconstitucionalidade dos processos seletivos estabelecendo outros critérios, para que todos tenham igualdade de oportunidades, atendendo às exigências constitucionais. Isso não significa anular as políticas universalistas, no entanto, a defesa da adoção de políticas de ação afirmativa não nega o fato de que elas devem ser complementadas por programas de reestruturação da educação pública, o que exige políticas adequadas e vultosos investimentos.

Realmente, é preciso elevar o padrão geral do ensino, mas, sobretudo, romper o abismo entre as escolas de qualidade particulares e 
as escolas públicas majoritariamente de má qualidade. Indubitavelmente, o argumento da justiça distributiva revela que não há dicotomia: as políticas universalistas devem ser complementadas por políticas de ação afirmativa, pois as primeiras não foram capazes de diminuir a distância entre negros e brancos.

O Brasil experimentou grandes avanços a partir da Constituição de 1988, sobretudo a partir de seus instrumentos universalistas. Em que pese a melhoria do acesso aos serviços públicos em geral, os negros estão em desvantagem em todos os indicadores sociais. As políticas universalistas, embora tenham produzido efeitos sociais favoráveis, não reduziram as desigualdades entre negros e brancos, devendo ser articuladas e complementadas por políticas de ação afirmativa voltadas para promover a igualdade entre as raças.

Para Sarmento (2006), a redução das desigualdades entre negros e brancos inspira benefícios para todas as sociedades, uma vez que as políticas de ação afirmativa possuem um papel pedagógico, no sentido de melhorar as relações entre as etnias, reduzindo os ressentimentos e as tensões. Em suma, o autor leciona que as instituições que implementam políticas de ação afirmativa tornam-se mais abertas e plurais, inspirando um contato paritário entre indivíduos de diferentes etnias.

Ademais, a própria Constituição Federal prevê duas políticas de ação afirmativa: o dever estatal de resguardar o mercado de trabalho da mulher (art. 7, inciso XX) e a reserva de vagas em concursos públicos para pessoas portadoras de deficiência (art. 37, inciso VIII) (BRASIL, 1988). Feitas essas considerações, passamos a examinar o julgamento da ADPF no 186 à luz do diálogo Honneth-Fraser.

\section{O STF e o julgamento da ADPF n. 186 à luz do diálogo Honneth-Fraser}

O Ministro Ricardo Lewandowski, relator do processo relativo à ADPF n 186, salientou que "a Constituição de 1988, ao mesmo tempo em que estabelece a igualdade de acesso, o pluralismo de ideias e a 
gestão democrática como princípios norteadores no ensino, também acolhe a meritocracia como parâmetro para a promoção aos seus níveis mais elevados" (BRASIL, 2012a).

Como se sabe, o artigo 207 garante às universidades, entre outras prerrogativas funcionais, a autonomia didático-científica e administrativa, tendo por base o tripé ensino-pesquisa- extensão. 0 argumento da autonomia administrativa das universidades foi resgatado por Lewandowski e Fux. Para Fux, a ideia não é pretender a supressão da supremacia do parlamento em nome de uma autonomia universitária contrária à soberania popular, mas permitir a coexistência das políticas de ação afirmativa nas esferas administrativa e legislativa. Portanto, as políticas de cotas implementadas pelas universidades não feririam a reserva legal, pois teriam fulcro na Constituição, na legislação federal e em atos administrativos ${ }^{8}$.

De fato, Lewandowski sublinha que "uma universidade predominantemente branca, em segundo lugar, falha na sua missão de constituir um ambiente passível de favorecer a cidadania, a dignidade humana, a construção de uma sociedade livre, justa" (BRASIL, 2012). E mais: "uma sociedade que não integra todos os grupos sociais dificilmente produzirá conhecimento que atenda aos excluídos, reforçando apenas as hierarquias e desigualdades que têm marcado nossa sociedade desde o início de nossa história" (BRASIL, 2012).

Sob essa ótica, Lewandowski conclui que a metodologia de seleção diferenciada visa assegurar que a comunidade acadêmica e a sociedade sejam beneficiadas pelo pluralismo de ideias, um dos fundamentos do Estado brasileiro, conforme art. $1^{\circ}$, inciso V, da Constituição. Tal raciocínio assemelha-se à argumentação desenvolvida por Sandra O'Connor em seu voto majoritário no caso Grutter v. Bolinger (ESTADOS UNIDOS, 2003), julgado pela Suprema Corte Norte-Americana. Segundo Sandra

8 Nesse sentido, citou normas criadas com essa finalidade: as Leis no 9.394/96 (BRASIL, 1996), no 10.172/2001 (BRASIL, 2001), no 10.558/2002 (BRASIL, 2002), no 10.678/2003 (BRASIL, 2003) e, por fim, a Convenção Internacional sobre a Eliminação de Todas as Formas de Discriminação Racial, internalizada pelo Decreto no 65.810/69 (BRASIL, 1969). 
O'Connor, haveria um interesse imprescindível da Universidade de Michigan de obter os benefícios educacionais de um corpo estudantil diverso, decorrente da formação de uma "massa crítica" de estudantes minoritários.

Nesse ponto, tal contato paritário entre as etnias é fundamental para inspirar um sentido de solidariedade cívica, que é pressuposto para a ideia de liberdade social descrita por Honneth (2011). Assim, o argumento do pluralismo é fundamental, não apenas no que se refere ao estabelecimento de relações humanas ricas e plurais, como também para aprimorar a pesquisa acadêmica e o processo de construção do conhecimento nas universidades.

É possível realizar pesquisa acadêmica de boa qualidade com grupos etnicamente e culturalmente homogêneos? Evidentemente que não. As políticas de ação afirmativa são instrumentos legítimos para que a pesquisa acadêmica e o processo de construção do conhecimento sejam plurais. A diversidade de atores é fundamental para aprimorar o ensino e a pesquisa acadêmica, pois, a partir da colaboração de pessoas com perspectivas diversas, é possível a produção de um saber diversificado.

Nesse cenário, Lewandowski leciona que a Constituição de 1988, ao qualificar o crime de racismo como inafiançável, partiu de um conceito de raça considerado não como fato biológico, mas como categoria histórico-social. Portanto, se a raça foi utilizada para construir hierarquias, também deverá ser utilizada para desconstruí-las, incrementando a inclusão social de grupos tradicionalmente excluídos.

Ademais, considerou que o critério da temporariedade foi cumprido, uma vez que o Programa de Ações Afirmativas instituído pelo CONSUNI da UNB estabeleceu a necessidade de sua reavaliação após o transcurso do período de 10 anos. No mesmo sentido, a juíza Sandra O'Connor, no referido caso Grutter v. Bollinger (ESTADOS UNIDOS, 2003), salientou que, provavelmente em 25 anos, o uso de critérios raciais não seja mais necessário após o cumprimento de seus fins inclusivos. 
Desse modo, compreendemos, como Lewandowski e Fux, que a reserva de $20 \%$ das vagas da UNB para estudantes negros e de um pequeno número para índios de todos os estados brasileiros satisfaz o requisito da proporcionalidade. No entanto, o raciocínio argumentativo do Ministro Lewandowski poderia ter alcançado maior profundidade jurídica na explicitação dos subprincípios da adequação, necessidade e proporcionalidade em sentido estrito. A Ministra Rosa Weber, por sua vez, não vislumbrou violação ao subprincípio da necessidade, pois a política de cotas seria imediata e temporária, tendendo a desaparecer à medida que as discrepâncias sociais fossem diminuídas (BRASIL, 2012h).

Nesse contexto, consagrou-se também o argumento vinculado à promoção de justiça distributiva com vistas à inclusão social de grupos excluídos ou marginalizados. Nessa linha de raciocínio, sustentamos que o instrumental teórico de Fraser é relevante para a implementação de políticas de ação afirmativa, pois, de um lado, permite combater as assimetrias econômicas entre as raças, ampliando as possibilidades de acesso dos afrodescendentes ao mercado de trabalho e ao ensino superior; de outro lado, possibilita valorizar os seus direitos culturais, desconstruindo ações socioestatais que incrementam o estigma e o preconceito.

Nesse particular, o Ministro Luiz Fux destacou que a opressão racial no Brasil deixou raízes que se refletem no campo da escolaridade, com graus alarmantes de diferenciação entre estudantes afrodescendentes e brancos. Para Fux, a abolição da escravatura não seguida por políticas públicas ensejou uma suposta democracia racial que instituiu desigualdades, forjando uma falsa consciência racial brasileira, difundindo todo um elenco de concepções etnocêntricas (BRASIL, 2012b).

É de se mencionar que o mito da democracia racial articulouse ao ideal do branqueamento no processo de construção da nação, sobretudo com a política de estímulo à imigração europeia entre 1870 e o início do século passado. A ideia era atrair trabalhadores europeus, 
com o objetivo de modernizar o país. De fato, o ideal do branqueamento encontrou receptividade, não apenas no âmbito da política imigratória, mas também no imaginário dos cidadãos brasileiros, impulsionando processos simbólicos de depreciação da cultura e história negras ${ }^{9}$.

Nesse quadro teórico, o Ministro Gilmar Mendes aduziu que o projeto da UNB seria pioneiro dentre as universidades federais e, portanto, suscetível a questionamentos e aperfeiçoamentos. Analisando a questão do quem da demanda de justiça envolvida, ressaltou a possibilidade de surgir dúvida quanto ao critério puramente racial, permitindo-se uma possível distorção: pessoas negras com desenvolvimento educacional adequado entram nas universidades pelas cotas, pois não se leva em conta o referencial social (BRASIL, 2012f).

Em face dessa leitura, os Ministros Gilmar Mendes e Marco Aurélio destacaram que a arbitrariedade das comissões de administração e possíveis distorções não consubstanciam base definitiva contra a adoção da política de cotas. As distorções poderão ocorrer, pois se trata de um modelo que está sendo experimentado e cujas distorções serão reveladas, devendo a universidade promover seu aperfeiçoamento.

Assim, defendemos que o aperfeiçoamento do sistema de cotas, no que se refere à moldura adequada de justiça, deve satisfazer à dimensão da representação e contar com o assentimento de todos os concernidos em um processo de deliberação justo e aberto. Ademais, deve estar atento às experiências internacionais de concretização do sistema de cotas raciais, pois, segundo Fraser (ano?), o princípio de todos os afetados não coincide necessariamente com o princípio do Estado territorial.

9 O efeito da articulação desses dois ideais foi a ideia de antirracismo, pois evitar falar sobre a categoria raça seria uma forma de evitar problemas raciais. Nesse sentido, é clara a assertiva de Bernardino (2004, p. 17-18): “A recusa em falar de raça não significa que o Estado brasileiro não tenha se envolvido nas ações pertinentes à raça. A política de branqueamento que aqui vigorou é uma prova irrefutável de que existiu um sistema formal de favorecimento da população branca recém-chegada. Além disso, o Estado brasileiro sempre fez questão de divulgar interna e externamente uma imagem de país harmonioso sob o ponto de vista das relações raciais, utilizando estrategicamente o carnaval como símbolo de integração racial." 
De fato, a Constituição afirma que o principal critério de acesso ao ensino superior é o mérito, entretanto, tradicionalmente, o mecanismo para aferição do mérito é o vestibular, que não é meritocrático. Ele é uma forma de premiar o investimento que os pais fizeram em relação aos filhos. Ora, não podemos nos utilizar de recursos públicos numa sociedade tão desigual e atribuí-los como prêmio aos filhos de pais que tiveram condições financeiras para investir na formação deles, especialmente em uma educação voltada para atender certos critérios.

Diante dessa estrutura conceitual, Celso de Mello ponderou que, de acordo com a Conferência de Durban, o racismo é uma grave violação de todos os direitos humanos e um injusto obstáculo ao gozo pleno e integral de tais direitos e prerrogativas, significando denegação ao dogma de que todos os seres humanos nascem livres e iguais em dignidade e direitos.

Outrossim, percebemos a relevância do voto do Ministro, pois, a partir dele, podemos visualizar como a discussão atual sobre o quem da temática das cotas raciais ultrapassa a moldura keynesiana-westfaliana dos públicos nacionais. As demandas por reconhecimento reivindicadas pelo movimento negro cada vez mais ultrapassam os limites do Estado nacional, pois os reivindicantes não se restringem a problematizar temáticas relativas apenas às relações entre cidadãos e Estado.

Nesse sentido, o Ministro ressaltou que não há democracia sem igualdade étnico-racial e citou importantes documentos internacionais subscritos pelo Brasil, como a Convenção Internacional sobre Eliminação de Todas as Formas de Discriminação Racial, a Declaração Universal dos Direitos da Pessoa Humana e os Pactos Internacionais sobre Direitos Civis, Políticos, Econômicos, Sociais e Culturais de 1966.

Sob esse aspecto, um debate como esse implica reflexão sobre direitos constitucionais mais fundamentais, de forma que o STF tem contribuído muito para aperfeiçoar a percepção de pluralidade e criação de um espaço democrático de debate em que diferentes perspectivas se sustentam. Discute-se a raça não como elemento genético, mas como 
construção social que torna grande parcela da população brasileira invisível e segregada.

Nessa perspectiva, defendemos que políticas de ação afirmativa devem estar desvinculadas das experiências emotivas de sofrimento vivenciadas pelo sujeito, tais como descritas por Honneth (2003b), porquanto a expansão dos processos intersubjetivos por reconhecimento mútuo pode efetivar-se plenamente por meio da concepção de "paridade de participação", configurada por Fraser (2008).

Em síntese, a autora pretende contrapor-se a uma perspectiva afirmativa, adotando uma postura desconstrutiva, que visa combater padrões institucionalizados de valores culturais, por meio dos quais determinados grupos são impedidos de alcançar pleno reconhecimento. Honneth (2003b), por sua vez, ao estabelecer que o objetivo primordial da Teoria Crítica seria garantir os pressupostos intersubjetivos voltados para resguardar a autorrealização individual, deixa "a questão central de como evitar as relações arbitrárias de dominação social e dominação político-jurídica em segundo plano" (WERLE; MELO, 2013).

Portanto, sustentamos que as reivindicações de reconhecimento do movimento negro devem estar desvinculadas de demandas por autorrealização, sendo mais efetivas ao focarem nos pressupostos que garantem a paridade de participação de minorias raciais. É mister frisar que os Ministros Ayres de Brito e Cesar Peluso divergiram no tocante ao argumento da justiça compensatória, negando a ideia de que a nação deva pagar pelos erros de seus antepassados. Sustentamos que as ações afirmativas não devem ser compreendidas como instrumentos de compensação, mas como fatores de integração voltados para desconstruir mecanismos institucionais vinculados a uma discriminação atual que impedem a paridade de participação de afrodescendentes na esfera pública.

A terceira dimensão da justiça estabelecida por Fraser (2009) corresponde à esfera da representação e foi atendida de forma satisfatória no julgamento da ADPF $n^{\circ} 186$, tendo em vista a realização de audiências públicas convocadas pelo STF, nas quais as mais variadas entidades 
sociais, associações e movimentos sociais envolvidos puderam se manifestar, em um debate franco e aberto sobre o uso de critérios raciais nos programas de admissão das universidades brasileiras.

De fato, segundo Fraser, os movimentos sociais, ao reivindicarem o direito de determinar o quem, problematizam o como hegemônico, tematizando a criação de procedimentos novos e não hegemônicos relativos a disputas de enquadramento de justiça. Tal questão pode ser exemplificada na questão da discussão sobre cotas raciais no que se refere ao quem destinatário de tais benefícios e em relação a quais critérios para definição do quem. Enquanto alguns amici, nas audiências públicas, defendiam o critério da autodeclaração, outros sustentavam a instauração de uma comissão de avaliadores.

Indubitavelmente, o movimento negro, por meio de procedimentos não hegemônicos, tem discutido sobre os critérios para definição do quem, o que revela a importância da dimensão da representação, tal como descrita por Fraser. No entanto, apesar desse frutífero debate estabelecido em sede judicial, percebemos um déficit de representação de negros nos espaços de representação política nacional. Dos 40 Ministérios do Governo Dilma, somente o da Igualdade Racial tem como titular da pasta uma mulher negra. Dentre as 50 principais estatais nacionais, somente a BAHIAGÁS tem como presidente um negro. Enquanto $50,6 \%$ dos brasileiros são negros, apenas $8,3 \%$ deles compõem o Congresso Nacional.

\section{Conclusão}

Diante do exposto, depreende-se que a atribuição de direitos com base na raça mediante políticas de ação afirmativa é legítima, pois se trata de uma categoria social que explica as relações assimétricas no Brasil. A categoria raça é uma construção social que marca profundamente as relações sociais no Brasil, permitindo a atribuição de direitos e vantagens a certos indivíduos, visando desconstruir hierarquias sociais. 
Sob essa ótica, para concretizar os direitos fundamentais dos afrodescendentes por meio de políticas de cotas raciais, é fundamental resgatar a perspectiva teórica de Fraser (ano?). Tal modelo permite desconstruir mecanismos institucionais na esfera da distribuição, do reconhecimento e da representação que impedem uma participação efetiva dos afrodescendentes como pares nas interações sociais do espaço público.

Nesse ponto, o modelo de status delineado por Fraser (2003) pretendia desvincular-se da perspectiva identitária delineada por Honneth (2003b), porquanto este, ao enfatizar a dimensão psicológica do reconhecimento, terminava por negligenciar as estruturas sociais institucionalizadas que impediam a paridade de participação de grupos minoritários. A questão fundamental, portanto, não é focalizar o potencial das experiências de sofrimento, como pretendia Honneth (2003b), mas as efetivas implicações das relações raciais assimétricas na esfera da interação social.

Nesse cenário, defendemos, com base em Fraser (2008), que o objetivo emancipatório da Teoria Crítica diz respeito à compreensão de que todos os afetados devem ter iguais chances de se engajar em lutas participativas na esfera pública para definir o que vale como reconhecimento. A questão é: "alguns deles foram excluídos ou marginalizados como consequência de um arranjo social injusto?" (FRASER, 2008, p. 331-2). É papel da Teoria Crítica identificar os impedimentos à justa contestação sobre o significado do reconhecimento.

É justamente nas arenas discursivas, estabelecidas pelos contrapúblicos subalternos, que o movimento negro tem articulado, de forma mais renovada, a compreensão acerca de sua realidade no que se refere à discussão de temas relacionados a racismo, cotas e discriminação no mercado de trabalho, minimizando a profunda situação de desvantagem na esfera pública oficial.

No entanto, a partir da reviravolta teórica de Honneth, em 2011, percebemos que a adoção de políticas de cotas raciais também se relaciona intimamente à ideia de liberdade social, expressando um 
mecanismo por meio do qual as instituições sociais estabelecem papéis sociais renovados aos indivíduos que irão moldar intersubjetivamente a construção de suas identidades autônomas.

Com efeito, tal princípio encontra-se implícito nos votos dos Ministros Marco Aurélio e Carmen Lúcia, ao ressaltarem que a Constituição partiria da igualdade estática para o processo dinâmico de igualação. O Ministro Marco Aurélio sublinhou que a Constituição não incorporou uma postura estática, meramente negativa, da igualdade, mas uma posição ativa, eficaz, dinâmica, pois os verbos "construir", "garantir", "erradicar" e "promover" implicam uma mudança de ótica ao denotarem ação.

Desse modo, não basta não discriminar: é preciso viabilizar as mesmas oportunidades, traduzindo-se em uma postura afirmativa de transformação social, com o objetivo de eliminar a pobreza, uma das maneiras de discriminação, visando ao bem de todos, e não apenas daqueles nascidos em berço de ouro. No mesmo sentido, a Ministra Carmem Lúcia sublinhou a responsabilidade social e estatal para que o princípio da igualdade dinâmica fosse cumprido objetivamente.

Se, em Luta por Reconhecimento, a capacidade do indivíduo de desenvolver sua concepção de bem estava associada à dimensão das relações intersubjetivas de reconhecimento, a partir de 2011, conectase às instituições sociais fundamentais. Agora, para Honneth (ano?), o princípio essencial de justiça passa a ser a liberdade. Cada uma das esferas da sociedade está constituída e legitimada por esse valor.

Nesse contexto, nas palavras de Sobottka (2013, p. 160): "Embora essa liberdade seja sempre concebida como individual, suas distintas compreensões encontram sua expressão como promessas consagradas historicamente através de lutas sociais em instituições da sociedade." $E$ conclui: "Essas promessas institucionalizadas são a base normativa das exigências de justiça."

Nessa linha de raciocínio, uma sociedade justa é aquela que satisfaz as expectativas normativas de seus cidadãos quanto à 
concretização da ideia de liberdade. Tal efetivação objetiva do princípio da igualdade pode ser compreendida, à luz da teoria de Honneth, como a cristalização de promessas consagradas historicamente nas instituições sociais. O exemplo das cotas raciais serve para ilustrar a ideia de Honneth (ano?) segundo a qual os papéis sociais estabelecidos pelas instituições irão moldar a liberdade social dos indivíduos.

Outrossim, para superar o racismo no Brasil, é necessário corrigir o déficit de representação política dos negros nas instâncias de poder, razão pela qual percebemos a relevância do novo modelo teórico tridimensional de Fraser (2010) para a análise dos desafios propostos pelo movimento negro. Como salientamos, não obstante o amplo debate estabelecido nas audiências públicas por ocasião do julgamento da ADPF no 186, esse déficit de representação de negros nos espaços de representação política nacional ainda é uma herança da sociedade escravocrata, impedindo a construção de uma democracia plena no Brasil.

\section{Referências}

BENJAMIM, César. Tortuosos caminhos. In: Fry P, Maggie Y, Maio MC, Monteiro S, Santos RV. Divisões perigosas: políticas raciais no Brasil Contemporâneo. Rio de Janeiro: Civilização Brasileira, 2007. p. 27-33.

BRASIL. Decreto $n^{\circ}$ 65.810, de 8 de dezembro de 1969. Promulga a Convenção Internacional sobre a Eliminação de todas as Formas de Discriminação Racial. Disponível em: <http://legis.senado.gov.br/ legislacao/ListaTextolntegral.action?id=94836>. Acesso em: 1 mar. 2014.

BRASIL. Decreto ${ }^{\circ} \mathbf{4 . 8 8 6}$, de 20 de novembro de 2003. Institui a Política Nacional de Promoção à Igualdade Racial e dá outras providências. Disponível em: <http://www.planalto.gov.br/ccivil_03/decreto/2003/ D4886.htm>. Acesso em: 1 mar. 2014.

BRASIL. Decreto $\mathbf{n}^{\circ}$ 6.872, de 4 de junho de 2009. Aprova o Plano Nacional de Promoção à Igualdade Racial e institui seu comitê de 
articulação e monitoramento. Disponível em: <http://www.planalto.gov. br/ccivil_03/_Ato2007-2010/2009/Decreto/D6872.htm>. Acesso em: 1 mar. $20 \overline{14}$.

BRASIL. Constituição (1988). Constituição da República Federativa do Brasil de 1988. Disponível em: <http://www.planalto.gov.br/ccivil_03/ constituicao/constituicao.htm>. Acesso em: 1 mar. 2014.

BRASIL. Lei $\mathbf{n}^{\circ} \mathbf{1 2 . 2 8 8}$, de 20 de julho de 2010. Institui o estatuto da Igualdade Racial. Disponível em: <http://www.planalto.gov.br/ccivil_03/_ Ato2007-2010/2010/Lei/L12288.htm>. Acesso em: 1 mar. 2014.

BRASIL. Lei n $^{\circ}$ 12.990, de 9 de junho de 2014. Reserva aos negros $20 \%$ (vinte por cento) das vagas oferecidas nos concursos públicos para provimento de cargos efetivos e empregos públicos no âmbito da administração pública federal, das autarquias, das fundações públicas, das empresas públicas e das sociedades de economia mista controladas pela União. Disponível em:< http://www.planalto.gov.br/ccivil_03/_ Ato2011-2014/2014/Lei/L12990.htm>. Acesso em: 10 jun. 2014.

BRASIL. Supremo Tribunal Federal. Argüição de Descumprimento de Preceito Fundamental $n^{\circ}$ 186. Voto do Relator: Ministro Ricardo Lewandowski. Brasília-DF. Julgamento: 25 e 26/04/2012a. Disponível em: <http://www.stf.gov.br>. Acesso em: 4 out. 2012.

BRASIL, Supremo Tribunal Federal. ADPF $\mathbf{n}^{\circ}$ 186. Voto do Relator: Min. Ricardo Lewandowski. Brasília-DF. Julgamento: 25 e 26/04/2012a. Disponível em: <http://www.stf.jus.br/arquivo/informativo/documento/ informativo663.htm\#Políticas de ação afirmativa e reserva de vagas em universidades públicas - 19>. Acesso em: 4 out. 2012.

BRASIL. Supremo Tribunal Federal. Argüição de Descumprimento de Preceito Fundamental $\mathbf{n}^{\circ}$ 186. Voto do Min. Luiz Fux. Brasília-DF. Julgamento: 25 e 26/04/2012b. Disponível em: <http://www.stf.jus.br/ arquivo/informativo/documento/informativo663.htm\#Políticas de ação afirmativa e reserva de vagas em universidades públicas - 19>. Acesso em: 4 out. 2012.

BRASIL. Supremo Tribunal Federal. Argüição de Descumprimento de Preceito Fundamental $\mathbf{n}{ }^{\circ}$ 186. Voto do Marco Aurélio. Brasília-DF. 
Julgamento: 25 e 26/04/2012c. Disponível em: <http://www.stf.jus.br/ arquivo/informativo/documento/informativo663.htm\#Políticas de ação afirmativa e reserva de vagas em universidades públicas - 19> Acesso em: 4 out. 2012.

BRASIL. Supremo Tribunal Federal. Argüição de Descumprimento de Preceito Fundamental $\mathbf{n}^{\circ}$ 186. Voto do Min. Carlos Ayres de Britto. Brasília-DF. Julgamento: 25 e 26/04/2012d. Disponível em: <http://www. stf.jus.br/arquivo/informativo/documento/informativo663.htm\#Políticas de ação afirmativa e reserva de vagas em universidades públicas - 19>. Acesso em: 4 out. 2012.

BRASIL. Supremo Tribunal Federal. Argüição de Descumprimento de Preceito Fundamental $\mathbf{n}^{\circ}$ 186. Voto do Min. César Peluso. Brasília-DF. Julgamento: 25 e 26/04/2012e. Disponível em: <http://www.stf.jus.br/ arquivo/informativo/documento/informativo663.htm\#Políticas de ação afirmativa e reserva de vagas em universidades públicas - 19> Acesso em: 4 out. 2012.

BRASIL, Supremo Tribunal Federal. Argüição de Descumprimento de Preceito Fundamental $n^{\circ}$ 186. Voto do Min. Gilmar Mendes. BrasíliaDF. Julgamento: 25 e 26/04/2012f. Disponível em: <http://www.stf.jus.br/ arquivo/informativo/documento/informativo663.htm\#Políticas de ação afirmativa e reserva de vagas em universidades públicas - 19>. Acesso em: 4 out. 2012.

BRASIL, Supremo Tribunal Federal. Argüição de Descumprimento de Preceito Fundamental $n^{\circ}$ 186. Voto do Min. Celso Mello. Brasília-DF. Julgamento: 25 e 26/04/2012g. Disponível em: <http://www.stf.jus.br/ arquivo/informativo/documento/informativo663.htm\#Políticas de ação afirmativa e reserva de vagas em universidades públicas - 19>. Acesso em: 4 out. 2012.

BRASIL. Supremo Tribunal Federal. Argüição de Descumprimento de Preceito Fundamental $\mathbf{n}^{\circ}$ 186. Voto da Ministra Rosa Weber. BrasíliaDF. Julgamento: 25 e 26/04/2012h. Disponível em: < http://www.stf.gov. br>. Acesso em: 4 out. 2012. 
BRASIL, Supremo Tribunal Federal. ADPF $\mathbf{n}^{\circ}$ 186. Voto da Min. Rosa Weber. Brasília-DF. Julgamento: 25 e 26/04/2012h. Disponível em: <http://www.stf.jus.br/arquivo/informativo/documento/informativo663. htm\#Políticas de ação afirmativa e reserva de vagas em universidades públicas - 19>. Acesso em: 4 out. 2012.

CARTA de cento e treze cidadãos anti-racistas contra as leis raciais. (Carta) Brasília, 2012 [para] Gilmar Mendes. Disponível em: <http:// culturaeducacao.blogspot.com.br/2008/05/sobre-cotas-raciais.html> Acesso em: 4 out. 2012.

ESTADOS UNIDOS. Suprema Corte. Petition for the Writ of Certiorari. Grutter v. Bollinger. 539 U.S 306. Barbara Grutter v. Lee Bollinger. Opinião majoritária: William Rehnquist. Washington D.C. Decidido em: 23 jun. 2003.

FRASER, Nancy. Da redistribuição ao reconhecimento: dilemas da justice na era pós-socialista. In: SOUZA, Jessé. Democracia hoje: novos desafios para a teoria democrática contemporânea. Brasília: UNB, 2001. p. 246-282.

. Distorted beyound all recognition: a rejoinder to Axel Honneth. In: FRASER, Nancy; HONNETH, Axel. Redistribution or recognition? a political philosophical exchange. London: Verso, 2003a. p. 295-307.

. Justice social in the age of identity politics. In: FRASER, Nancy; HONNETH, Axel. Redistribution or recognition? a political philosophical exchange. London: Verso, 2003b. p. 7-109.

. Prioritizing justice as participatory parity: a reply to Kompridis and Forst. In: OLSON, Kevin. Adding Insult to Injury: Nancy Fraser debates her critics. London: Verso, 2008. p. 328-345.

. Reenquadrando a justiça em um mundo globalizado. Lua Nova, São Paulo, n. 77, p. 11-39, 2009.

Scales of justice: Reimagining political space in globalizing world. New York: Columbia University Press, 2010. 
FREYRE, Gilberto. Casa grande \& senzala. Rio de Janeiro: José Olympio, 1973.

GUIMARÃES, Antonio Sérgio. Racismo e anti-racismo no Brasil. São Paulo: Ed. 34, 1999.

HONNETH, Axel. Invisibility: on the epistemology of recognition. Supplement to the Proceedings of the Aristotelian Society, v. 75, n. 1, 2001, p. 1-13.

. Luta por reconhecimento. A gramática moral dos conflitos sociais. São Paulo: Ed. 34, 2003a.

- Redistribution as recognition: a response to Nancy Fraser. In: FRASER, Nancy; HONNETH, Axel. Redistribution or recognition. Londres/New York: Verso, 2003b. p.110-197.

The point of recognition: A rejoinder to the rejoinder. In: FRASER, Nancy; HONNETH, Axel. Redistribution or recognition. Londres/New York: Verso, 2003c. p. 237.

KOMPRIDIS, Nikolas. Struggling over the meaning of recognition. In: OLSON, Kevin. Adding Insult to Injury: Nancy Fraser debates her critics. London: Verso, 2008. p. 295-309.

$\mathrm{OKOCHI}$, Taiju. Freedom and Institution: Theory of justice as Hegelian "Sittlichkeitslehre" in A. Honneth's das Recht der Freiheit. Hitotsubashi Journal of Social Studies, Japan, v. 44, n. 1. p. 9-19, 2012. Disponível em: <http: // hdl.handle.net 100086/23189>.

SARMENTO, Daniel. A igualdade étnico-racial no direito constitucional brasileiro: discriminação de facto, teoria do impacto desproporcional e ação afirmativa. In: SARMENTO, Daniel. Livres e iguais - Estudos de direito constitucional. Rio de Janeiro: Lumen Juris, 2006. p. 139-166.

SOBBOTKA, Emil; SAAVEDRA, Giovani. Justificação, reconhecimento e justiça: tecendo pontes entre Boltanski, Honneth e Walzer. Civitas, Porto Alegre, v. 12, n. 1, p.126-144, 2012.

WERLE, Denilson; MELO, Rúrion. Um défict político do liberalismo hegeliano. Autonomia e reconhecimento em Honneth. In: MELO, Rúrion 
(Org.). A teoria crítica de Axel Honneth: reconhecimento, liberdade, justiça. São Paulo: Saraiva, 2013. p. 317-335.

Data de recebimento: 03/04/14 Data de aprovação: 21/05/14 